\title{
Daily, Monthly and Yearly Variability in Recruitment of a Guild of Coral Reef Fishes
}

\author{
David McB. Williams
}

Australian Institute of Marine Science, P.M.B. No. 3, Townsville, Queensland 4810, Australia

\begin{abstract}
Temporal variability in recruitment of a guild of pomacentrid fishes inhabiting small patch reefs and corals in the lagoon of One Tree Reef, Great Barrier Reef, was examined. The entire population of newly recruited pomacentrids on 66 sites was censused in situ at approximately 4 to 8 wk intervals from June 1976 to February 1979 and in April-May of 1980. Recruitment was seasonal, with all but 1 species recruiting primarily over summer. Rates of recruitment during summer were not constant but pulsed, with perhaps monthly frequency. One regularly-timed pulse (mid-summer) was studied in detail over 3 yr Calendric timing of the pulse was remarkably constant from year to year, with no clear relationship between recruitment and the time of the lunar month. Maximum daily rate of recruitment during the mid-summer pulse varied 15 -fold between years. The size of pulses varied as much as 6 -fold within years and the same pulses varied as much as 6 -fold among years. Annual recruitment of the common species varied as much as an order of magnitude over a $4 \mathrm{yr}$ period. The data indicate that (1) a large pulse of recruitment in 1 уг does not necessarily mean that other pulses in. the same year will be similarly large; (2) 1 large pulse alone is sufficient to make total recruitment in a year unusually successful; (3) while a good year for recruitment of 1 species may also be exceptionally good for other species, it need not necessarily be a good year for all species of the same guild.
\end{abstract}

\section{INTRODUCTION}

Coral reef fishes typically produce large numbers of offspring which are then dispersed by means of a pelagic larval phase (Sale, 1980). After a period of pelagic life varying from as little as $1 \mathrm{wk}$ to as long as 3 mo or more (Sale, 1980; J. Leis, pers. comm.), the larva settles to the reef surface, gains pigmentation and becomes a recruit to the community of reef residents.

A number of recent studies of communities of coral reef fish have emphasised the variable nature of juvenile recruitment and the important consequences for the structure of these communities (Russell et al., 1974; Sale and Dybdahl, 1975, 1978; Talbot et al., 1978; Williams, 1980). Sale, Talbot and co-workers have suggested that this variability, which prevents local communities from reaching an equilibrium structure, is a major factor maintaining the high diversity of reef fish communities (Sale, 1977; Talbot et al., 1978). A full understanding of the role of larval recruitment in determining the structure and stability of reef fish communities requires consideration of communities and settlement over a wide range of temporal and spatial scales (Williams and Sale, 1981).
The aim of this paper is to examine the variability of recruitment of a guild of fish over a range of temporal scales-from daily to annual variability over a 4 yr period. The guild comprises the pomacentrids occurring on small patch reefs and corals in lagoons of the Great Barrier Reef. This is part of a more extensive study of the role of larval recruitment in determining the distribution and abundance of these species among habitats within the One Tree lagoon (Williams, 1979, 1980 and in prep.; Williams and Sale, in prep.).

\section{MATERLALS AND METHODS}

\section{Study Sites and Their Assemblages}

This study was carried out in the Shark Alley area of One Tree Reef, Great Barrier Reef $\left(23^{\circ} 30^{\prime} \mathrm{S}\right.$, $\left.152^{\circ} 06^{\prime} \mathrm{E}\right)$; consult Williams and Sale (1981) for description of One Tree Reef and location of the study site. Shark Alley is a sandy channel approximately $500 \mathrm{~m}$ long and $100 \mathrm{~m}$ wide with a mean depth of $3 \mathrm{~m}$ at low water. It is at the edge of the One Tree lagoon and close to the windward crest of the reef. Many small patch reefs are scattered throughout the area, interspersed with large areas of sand. These patch reefs 
support the greatest diversity and abundance of pomacentrids found in the One Tree lagoon (Williams and Sale, in prep.). Within Shark Alley, the population dynamics of assemblages of pomacentrids in 66 sites comprising 57 small patch reefs and coralline rocks (up to $3.19 \mathrm{~m}^{3}$ ), 6 isolates shrub corals (to $0.05 \mathrm{~m}^{3}$ ) and 3 Acropora thickets (to $0.43 \mathrm{~m}^{3}$ ) were examined (Williams, 1979, 1980, and in prep.)

Small patch reefs and corals are the typical habitat of many of the species studied. Recruitment of pomacentrids to these habitats is primarily by larval settlement and there is little movement of fish between individual habitats after settlement. Juveniles can be readily censused since newly settled fish (within hours of settlement) are highly visible, being both brightly pigmented and active feeders on the plankton found a few centimetres above the substratum. They also restrict their movements to an area of approximately $10 \mathrm{~cm}$ $\times 10 \mathrm{~cm}$ so individual juveniles can be recognized and their appearance and persistence on the reefs recorded. The presence or absence of resident pomacentrids has no effect on the number of juveniles settling or on the mortality of juveniles in their first year (Williams, 1979, 1980). In addition, mortality of juveniles once recruited is very low (approximately $50 \%$, in the first year, including $20 \%$ in the first month) compared to the variability in recruitment and so reasonable estimates of settlement can be made sometime after settlement has occurred (Williams, 1979).

\section{Census Technique and Timing}

From June 1976 to February 1979, 4 trips a year were made to One Tree Reef. Each stay was generally of 6 to 7 wk and centred around November, January, May or August. An additional trip was made in April-May of 1980. In the text, the year 1977 refers to October 1976 October 1977, 1978 refers to October 1977 - October 1978 and 1979 to October 1978 - February 1979. Censuses were usually made at the beginning and end of each stay, resulting in 8 censuses $\mathrm{yr}^{-1}$ at 4 to $8 \mathrm{wk}$ intervals. The timing of the censuses divided the summer into 3 periods: mid-December to early January (early summer); January to early February (mid-summer); and mid-February to late April-early May (late summer).

The distribution and abundance of fishes was assessed by counting fish in situ using SCUBA equipment, with counts recorded underwater on perspex slates. All species on a habitat patch were counted and recounted on each dive until numbers were consistent

For each species, the fish censused were grouped into 5 size categories corresponding to the following approximate ages (Williams, 1979):
Stage I: $<2 \mathrm{wk}$ post-settlement

Stage II: $>2 \mathrm{wk},<3$ mo old

Stage III: 3 to 12 mo old

Stage IV: more than 1 year old but not fully-grown

Stage V: fully-grown fish

Stage I to III fish were referred to as juveniles; Stage IV and $V$ fish as adults.

I believe these age estimates were precise and accurate for all but 2 species, Dascyllus aruanus and Pomacentrus popei. The latter two had consistently slower rates of growth and higher rates of survivorship than the other species (Williams, 1979). As a result it was often difficult to distinguish fast growing fish 6 mo old from slow growing fish 12 to 18 mo old (all rated as Stage III). At the risk of underestimating total recruitment, the juvenile $D$. aruanus and $P$. popei referred to in this paper include only Stage I and II fish.

Two approaches were used in studying juvenile recruitment. First, monthly and seasonal trends were interpolated from the censuses made at the beginning and end of each trip. Second, daily censuses of all juvenile pomacentrids on the Shark Alley habitats were made during each mid-summer trip when recruitment was maximal. Recruitment in each habitat was estimated as the increase in number of Stage I and II individuals between censuses. Interpolation may underestimate recruitment in 2 ways. Transient individuals that both recruited and disappeared between successive censuses will be missed and the rapid replacement of individuals on the same site by conspecifics will be difficult to detect. The low postrecruitment mortality of the common species and the relatively low density and number of recruits per habitat minimize both forms of underestimation associated with this method. On the other hand, the relatively high post-recruitment mortality of Chromis nitida and Acanthochromis polyacanthus (in the order of $95 \%$ or more in the first year; Williams, 1979) would lead to a serious underestimate of settlement if the interpolation technique were used for these species. Consequently they were excluded from this analysis of settlement patterns.

\section{Year to Year Variability}

To permit comparisons of recruitment over 4 years, 2 different estimates of annual recruitment were considered (Table 2). Numbers of recruits were estimated by interpolation between censuses for 1977, 1978 and 1979 (such a comparison was not possible for 1980 due to lack of regular censusing). To estimate relative numbers recruiting in 1980, the number of juvenile fish present in April-May of 1977, 1978 and 1980 were 
compared (similar figures are not available for 1979). Year-to-year variability in recruitment of individual species was calculated by dividing the number of recruits in the year of greatest recruitment by the number in year of least recruitment. In cases where an extreme value of recruitment did not occur in 1980, the interpolated estimates of recruitment (Table $2 \mathrm{~A}$ ) were used. If an extreme situation was apparent in 1980, the number of juveniles present in April-May (Table 2B) was used as a conservative estimate of recruitment. Unfortunately, direct comparisons between recruitment in 1979 and 1980 cannot be made. For the 2 cases in which extremes of recruitment occurred in 1979 and 1980 (Pomacentrus amboinensis and $P$. wardi), an indirect comparison could be made. For example, estimated recruitment of $P$, amboinensis in 1979 was 2.8 times that of 1977 (Table 2A) and recruitment in 1977 was 3.2 times that in 1980 (Table 2B). Therefore recruitment of $P$. amboinensis in 1979 was approximately 9 times as great as that in $1980(2.8 \times 3.2)$.

\section{RESULTS}

A total of 1,690 pomacentrids, belonging to 19 species were recorded as recruiting in Shark Alley between October 1976 and February 1979. Of these fishes $94 \%$ recruited over summer between midDecember and early May.

Daily censuses of newly-settled pomacentrids were made during mid-summer. Numbers of fish settling during this period peaked sharply in late Januaryearly February in each of the 3 yr (Fig. 1). Timing of this pulse of recruitment was remarkably consistent from year to year (calendar dates) but showed no clear relationship with time of the lunar month. The greatest daily total of recruitment in 1979 was 15 times greater than that recorded in 1978 and 9 times greater than that of 1977.

It is probable that recruitment in early summer also occurred in a single distinct pulse. The similar size and the behaviour of juveniles recruiting in early summer and first censused in early Januar of 1977, 1978 and 1979 indicated that they were all probably less than $2 \mathrm{wk}$ post-settlement. This suggests that numbers recruiting peaked in late December-early January of each year. Whether recruitment in late summer occurred as one or more pulses is not known. The same periodicity in recruitment was observed in other areas of the One Tree lagoon (own obs.).

The number of pomacentrids recruiting during each of the 3 summer periods (pulses?) varied considerably both within years and between years (Fig. 2). Within years, numbers recruiting during each of the 3 periods

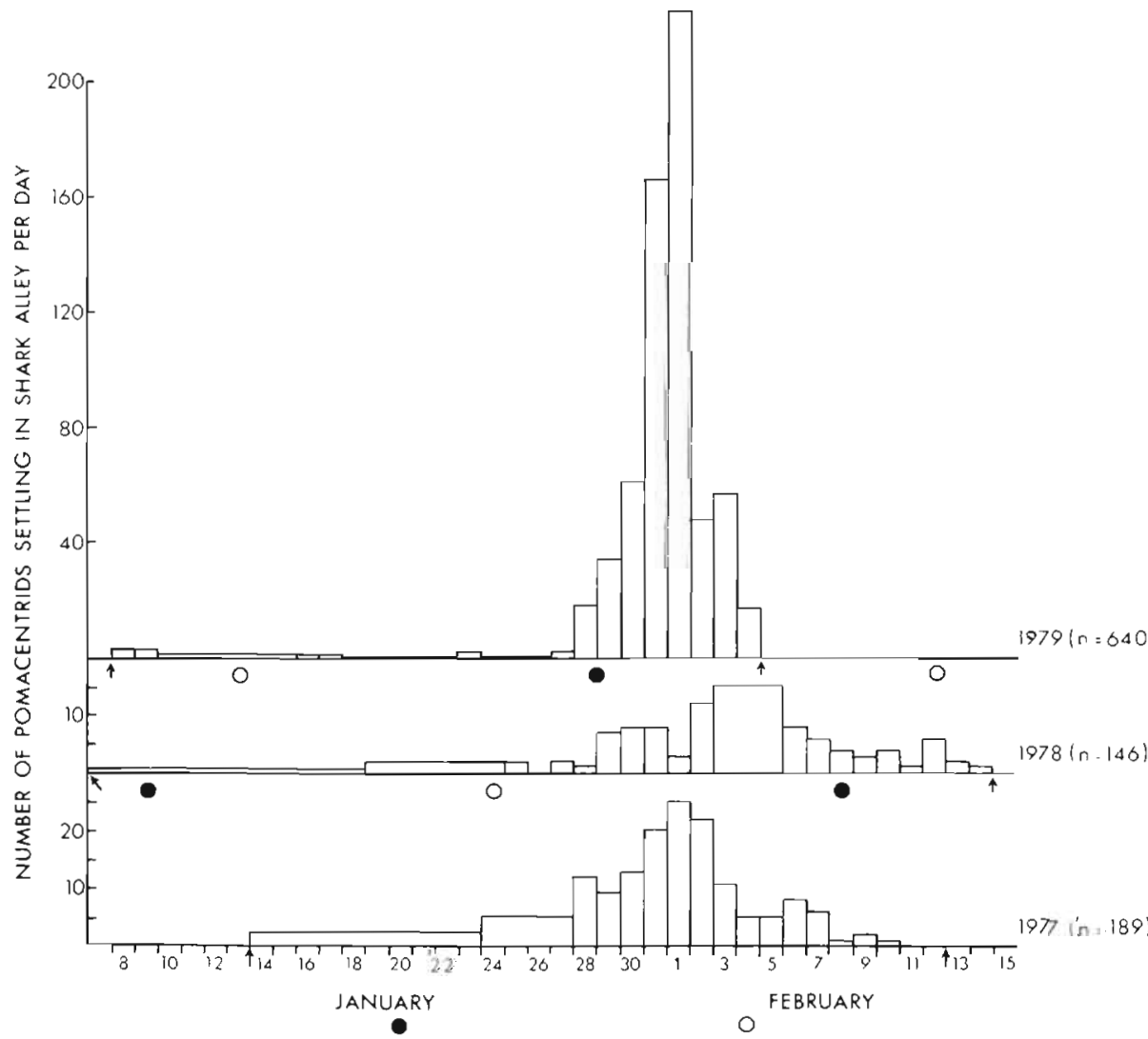

Fig. 1. Numbers of pornacentrids recruiting per day in 1977, 1978 and 1979. Where data from one or more days are combined, height of histogram is equal to mean settlement over that period. Arrows: beginning and end of census period. - Time of new moon; O time of full moon 


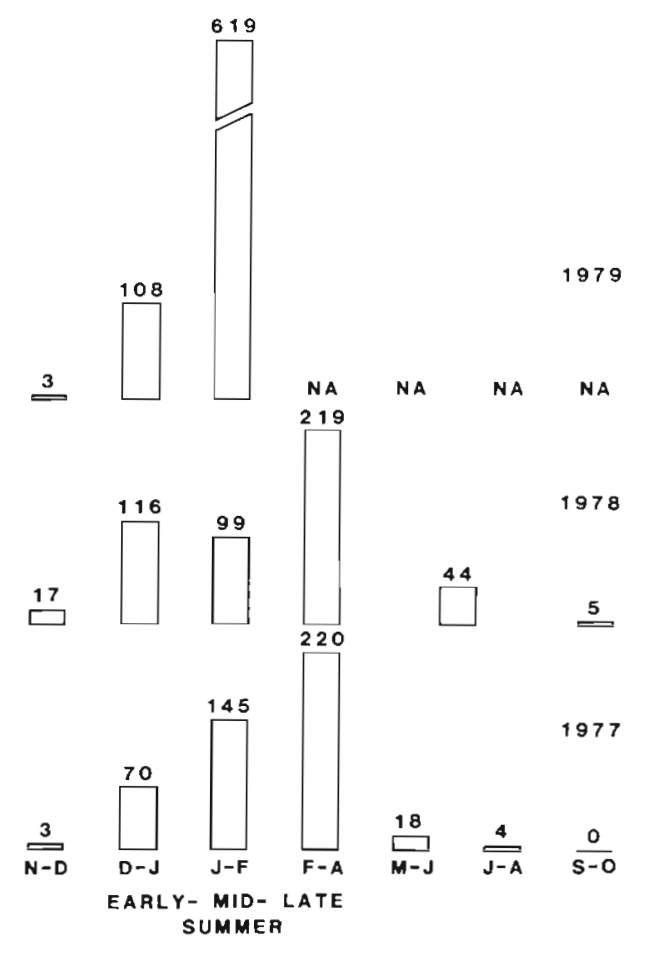

Fig. 2. Total numbers of juvenile pomacentrids (all species pooled) recruiting to Shark Alley habitats between censuses in 1977, 1978 and 1979. NA data not available

differed significantly in all 3 yr ( $\mathrm{x}^{2}$ comparison to even distribution, $x^{2}=77.59,58.29,359.18$ for 1977,1978 and 1979, $\mathrm{P}<0.01$ in all cases). Recruitment varied among periods as much as 6 -fold within years (early and mid-summer 1979). Between years, the greatest recruitment during any given period (mid-summer 1979) was almost 9 times smallest (early summer 1977).

Numbers recruiting during early summer differed significantly among the $3 \mathrm{yr}$ as did numbers recruiting in mid-summer $\left(x^{2}=12.33,576.12\right.$ respectively, $\mathrm{P}<0.01$ in each case). Recruitment in late summer did not differ significantly between the $2 \mathrm{yr}$ for which data is presented $\left(x^{2}=0.00, P>0.05\right)$. Censuses of a number of Shark Alley habitats (those on which most recruitment had been recorded in previous years) in May 1979 indicate that recruitment in late summer of that year was considerably less than that of the other 2 yr (P. J. Doherty, pers, comm.). Recruitment in a given period varied as much as 6 -fold between years.

None of the 3 summer periods had consistently larger, or smaller numbers of recruits than the other periods. Recruitment in late summer was greater than in the other periods in both years recorded (Fig. 2). However, the May 1979 censuses referred to above indicated that recruitment in late summer of that year was considerably less than the mid-summer recruitment.

Two species, Pomacentrus sp. (Allen, 1975, p. 214) and $P$. amboinensis, comprised $69 \%$ of all recruits. Seven species (Pomacentrus sp., $P$. amboinensis, Dascyllus aruanus, $P$. wardi, $P$. popei, $P$. australis and $P$. pavo) comprised $96 \%$ of the total; $81 \%$ of $P$. australis and at least $91 \%$ of each of the other 6 species recruited over the 3 summer periods.

Some consistent differences in the species composition of fish recruiting among the 3 summer periods did occur (Table 1). Pomacentrus amboinensis was always the commonest species in early and mid-summer and Pomacaentrus sp. the commonest in late summer (including 1979). No similarly consistent patterns could be detected for the less common species.

Recruitment in mid-summer of 1979 was exceptional compared to that of any other time during the study (Fig. 2). Four of the 7 most abundant species (Pomacentrus amboinensis, $P$. wardi, $P$. popei and $P$. australis) recruited in exceptionally large numbers - an order of magnitude larger than the mean over previous periods. Recruitment of Pomacentrus sp. was greater than usual for mid-summer but similar to that for late summer of the previous $2 \mathrm{yr}$. On the other hand, unusualiy few $P$. pavo and Dascyllus aruanus recruited over this period. No $P$. pavo were recorded to recruit and recruitment of $D$. aruanus was the lowest record for that species in any summer period.

Table 2 summarizes annual recruitment of pomacentrids by species and year. The total number of pomacentrids recruiting did not differ significantly between 1977 and $1978\left(x^{2}=1.84, P>0.05\right)$ but recruitment of 3 of the 7 most abundant species

Table 1. Species composition (\%) of recruits during 3 summer periods of settlement. NA not available

\begin{tabular}{|lrrrrrrrr}
\multicolumn{1}{c}{ Species } & \multicolumn{3}{c}{ Early summer } & \multicolumn{3}{c}{ Mid-summer } & \multicolumn{2}{c}{ Late summer } \\
& 1977 & 1978 & 1979 & 1977 & 1978 & 1979 & 1977 & 1978 \\
\hline Pomacentrus sp. & 0 & 10 & 5 & 26 & 20 & 19 & 72 & 53 \\
P. amboinensis & 51 & 34 & 46 & 48 & 37 & 56 & 15 & 16 \\
P. wardi & 0 & 19 & 8 & 5 & 10 & 9 & 0 & 1 \\
P. popei & 3 & 8 & 3 & 6 & 11 & 9 & 0 & 1 \\
Dascyllus aruanus & 14 & 11 & 19 & 6 & 9 & 0 & 6 & 21 \\
Miscellaneous & 32 & 18 & 19 & 9 & 13 & 7 & 7 & 8 \\
\hline
\end{tabular}


(Pomacentrus popei, Dascyllus aruanus and P. wardi) differed by more than a factor of 2 between these years. Significantly more fish recruited during 1979 than in either of the previous years $\left(x^{2}=62.28\right.$ and 43.01 for 1977, 1978 respectively $P<0.01$ both cases) despite the data for this year being incomplete, lacking data for late summer, autumn and winter. While 1979 was a particularly good year for recruitment of 4 of the 7 most abundant species ( $P$. amboinensis, $P$. australis, $P$. popei and $P$. wardi), 1980 was a particularly poor year for 3 of them ( $P$. amboinensis, Pomacentrus sp. and $P$. wardi).

Conservative comparisons of year-to-year variability in numbers of the 7 most abundant species recruiting were made according to the analysis described under 'Methods' and based on the data in Table 2 ( $A$ and B). Recruitment of all 7 species varied considerably among the $4 \mathrm{yr}$ (Table $2 \mathrm{C}$ ). There was an order-ofmagnitude difference between years of maximal and minimal recruitment for 2 species ( $P$. amboinensis and $P$. wardi) and no recruitment at all of $P$. pavo in 1977.
This study has shown further that recruitment within the breeding season of at least 1 guild is not uniform, but probably occurs in pulses with a period of approximately 1 mo. The year-to-year constancy in the timing of the mid-summer pulse is remarkable. The proximal causes of these pulses of recruitment are unclear. Such periodicity could be the result either of periodic adult spawning or factors directly affecting the larvae.

Spawning periodicity related to lunar cycles has been demonstrated for many tropical fishes and lunarrelated patterns of recruitment have been attributed to a few species (reviewed in Johannes, 1978, 1981; and Lobel, 1978). The timing of recruitment observed here is consistent with a monthly periodicity as might be expected for a lunar-related cycle but the calendric timing of at least the early summer and mid-summer recruitment is remarkably constant and the timing does not shift with the lunar cycle from year to year. Thus a factor other than the lunar cycle must determine the spawning time of adults if spawning periodicity is

Table 2. Two estimates of annual recruitment: (A) Numbers of fish recruiting during 1977, 1978, 1979 (interpolated between censuses); (B) numbers of juvenile fish (young-of-the-year) present in April-May of 1977, 1978, 1980; (C) ratio of maximum annual differences in recruitment to minimum annual recruitment (respective years in parentheses)

\begin{tabular}{|c|c|c|c|c|c|c|c|c|}
\hline \multirow{2}{*}{ Species } & \multicolumn{3}{|c|}{ (A) Number settling } & \multicolumn{3}{|c|}{ (B) Number of juveniles } & \multirow{2}{*}{\multicolumn{2}{|c|}{$\begin{array}{l}\text { (C) Max. recruitment/ } \\
\text { Min. recruitment }\end{array}$}} \\
\hline & 1977 & 1978 & 1979 & 1977 & 1978 & 1980 & & \\
\hline Pomacentrus amboinensis & 145 & 131 & 399 & 130 & 147 & 41 & 9 & $(79 / 80)$ \\
\hline Pomacentrus sp. & 208 & 162 & 122 & 189 & 162 & 55 & 3 & $(77 / 80)$ \\
\hline Dascyllus aruanus & 34 & 77 & 24 & 15 & 49 & 10 & 5 & $(78 / 80)$ \\
\hline P. wardi & 12 & 41 & 63 & 11 & 35 & 5 & 12 & $(79 / 80)$ \\
\hline P. popei & 11 & 23 & 61 & 3 & 17 & 12 & 6 & $(79 / 77)$ \\
\hline P. australis & 8 & 11 & 51 & 0 & 3 & 14 & 6 & $(79 / 77)$ \\
\hline P. pavo & 16 & 18 & 0 & 11 & 13 & 14 & $?$ & $(78 / 79)$ \\
\hline Miscellaneous & 26 & 37 & 10 & 24 & 34 & $\underline{9}$ & & \\
\hline Total & 460 & 500 & 730 & 383 & 460 & 160 & & \\
\hline
\end{tabular}

\section{DISCUSSION}

While many coral reef fishes have extended breeding seasons (Sale, 1977), seasonal peaks in breeding activity are well documented (reviewed in Johannes, 1978). Seasonal patterns in abundance of the larvae of coral reef fishes in the plankton have also been documented (Watson and Leis, 1974; Powles, 1975, cited in Luckhurst and Luckhurst, 1977); the seasonality of larval recruitment observed in this study has also been recorded for pomacentrids in other geographical areas and for other species (e.g. Russell et al., 1974, 1977; Kami and Ikehara, 1976; Yamamoto, 1976; Luckhurst and Luckhurst, 1977; Molles, 1978; Williams and Sale, 1981). The possible causes and adaptive value of this seasonality have been reviewed by Qasim (1956), Munro et al. (1973), Russell et al. (1977) and Johannes (1978). the direct cause of the observed timing of recruitment. Day-length is the only obvious factor that is constant on a given date from year to year. A monthly spawning periodicity triggered by some precise day-length would give the observed peaks of recruitment but is difficult to see the adaptive value of such spawning behaviour, or how a fish could be so sensitive to the small changes in day-length found at this latitude.

Timing of recruitment might reasonably be related to the size or the diel timing of the tides. The larger the tides, the greater the amount of water flowing over the reef crest and into the lagoon and hence the greater the probability of larvae getting into the lagoon from outside. A high tide at dusk might also be an optimal time for successful recruitment. The few observations of pomacentrids settling have been made at dusk (own obs.; P. J. Doherty, pers. comm.) and this timing might be related to an increased chance of larvae avoiding 
visually-oriented predators when settling (Johannes, 1978). However, tidal height is related to the lunarcycle and the diel timing of the tides is not constant at the same time each year. Neither factor is correlated with the patterns of recruitment.

It is thus difficult to relate the calendric timing of the pulses of recruitment either to adult spawning cycles or to tidal influences on larvae. A third possibility is that larvae are extremely patchily distributed, that the observed pulses represent the arrival of dense patches of larvae on the reef and the similar timing of their arrival was purely coincidental - a chance phenomenon. The true causes of the timing remain enigmatic and warrant further research.

While the constancy of timing of recruitment was notable, the variability in magnitude of recruitment at several different temporal scales was also notable. This variability is all the more remarkable for the relatively short period of the study. Maximum numbers of fish recruiting per day in mid-summer varied up to 15 -fold between years. The numbers of fish recruiting in different periods of summer (and hence probably in different pulses of recruitment) varied 6 -fold within a year and recruitment in any given period varied 6-fold among years. Annual recruitment of the common species varied as much as an order of magnitude among years. Similar variability in the year-to-year recruitment of other reef fishes has been recorded at One Tree Reef (Russell et al., 1977; Williams and Sale, 1981) and elsewhere (Hawaii: Gosline and Brock, 1960; Guam: Kami and Ikehara, 1976; Curacao: Luckhurst and Luckhurst, 1977).

The large annual fluctuations in recruitment are potentially major determinants of the size and species composition of local populations of coral reef fishes. While the importance of variable recruitment in determining the population densities of fishes has long been recognized by fisheries' biologists working on temperature and cold water species (e.g. Hjort, 1914), the importance of similar variability in determining densities of fishes on coral reefs has only recently been recognised (Talbot et al., 1978; Williams, 1980; Johannes, 1981; Doherty, 1982).

Almost nothing is known of the factors determining variability of settlement in fishes of coral reefs but considerable effort has been spent on relevant studies of recruitment in the cooler water fisheries. Some of this year-to-year variability can be attributed to variability in breeding success (fecundity) of the adult stock, but a large proportion is due to highly variable survivorship during the planktonic stages (Hempel, 1965; Parrish, 1973). Attempts have been made to correlate larval survivorship with a wide range of environmental factors but with only limited success (e.g. Dickson et al., 1974; Pinus, 1974; Ricker, 1975; Sutcliffe et al.
1976, 1977). Factors most likely to affect survivorship of coral reef fishes include those related to the availability of food, to predation, and to movement of water currents (Williams, 1979).

Three particular results from this study should be borne in mind during future studies of the factors influencing the magnitude of larval recruitment and the consequences of variable recruitment on the structure of communities of reef fish:

(1) A large pulse of recruitment in 1 year does not necessarily mean that other pulses in the same year will be similarly large;

(2) just 1 large pulse is sufficient to make total recruitment in a year exceptionally large;

(3) while a good year for recruitment of 1 species may also be exceptionally good for other species it is not necessarily good for all species of the same guild.

Acknowledgements. This is a contribution from the University of Sydney's One Tree Island Field Station. I thank P. J. Doherty for help in the field. H. Caffey, J. H. Choat, P. J. Doherty, P. F. Scale all read various versions of the manuscript and suggested significant improvements. Most of the field work was carried out while I was a graduate student at the University of Sydney, supported by a Commonwealth post-graduate research grant.

\section{LITERATURE CITED}

Allen, G. R. (1975). Damselfishes of the south seas, T. F. H. New Yersey

Dickson, R. R., Pope, J. G., Holden, M. J. (1974). Environmental influences on the survival of the North Sea cod. In: Blaxter, J. H. S. (ed.) Early life history of fish. SpringerVerlag, New York, pp. 69-80

Doherty, P. J. (1982). Coral Reef fishes: recruitment-limited assemblages? Proc. 4th Int. Coral Reefs Symposium, Manila, in press

Gosline, W. A., Brock, V E. (1960). A handbook of Hawaiian fishes, Hawaii Press, Honolulu

Hempel, G. (1965). On the importance of larval survival for the population dynamics of marine food fish. Calif. Coop. Oceanic. Fish. Invest. Rep. 10: 13-23

Hjort, J. (1914). Fluctuations in the great fisheries of northern Europe. Rapp. P.-v. Réun. Cons. int. Explor. Mer 20: 1-13

Johannes, R. E. (1978). Reproductive strategies of coastal marine fishes in the tropics. Env. Biol. Fish. 3: 65-84

Johannes, R. E. (1981). Using knowledge of the reproductive behaviour of reet and lagoon fishes to improve fishing yields. In: Bardach, J. E., Magnuson, J. J., May, R. C., Reinhart, J. M. (eds.) Fish behaviour and its use in the capture and culture of fishes, International Center for Living Aquatic Resources Management, Manila

Kami, H. T., Ikehara, I. I. (1976). Notes on the annual juvenile siganid harvest in Guam. Micronesica 12: 323-325

Lobel, P. S. (1978). Diel, Iunar and seasonal periodicity in the reproductive behaviour of the pomacanthid fish, Centropyge potteri, and some other reef fishes in Hawaii. Pacif. Sci. 32: 193-207 
Luckhurst, B. E., Luckhurst, K. (1977). Recruitment patterns of coral reef fishes on the fringing reef of Curacao, Netherlands Antilles. Can. J. Zool. 55: 681-689

Molles, M. C (1978). Fish species diversity on model and natural reef patches: experimental insular biogeography. Ecol. Monogr. 48: 289-305

Munro, J. L., Gaut, V. C., Thompson, R., Reeson, P. H. (1973). The spawning seasonality of Caribbean reef fishes. J. Fish Biol. 5: 69-84

Parrish, B. B. (1973). Fish stocks and recruitment. Proceedings of a Symposium held in Aarhus 7-10th July 1980. Rapp. P.-v. Réun. Cons. int. Explor. Mer 164

Pinus, G. N. (1974). Some factors influencing early survival and abundance of Clupeonella in the sea of Azov. In: Blaxter, J. H. S. (ed.) Early life history of fish. SpringerVerlag, New York, pp. 81-86

Powles, H. W. (1975). Abundance, seasonality, distribution and aspects of the ecology of some larval fishes off Barbados. Ph. D. thesis, McGill University, Canada

Qasim, S. Z. (1956). Time and duration of the spawning season in some marine teleosts in relation to their distribution. J. Cons. int. Explor. Mer 21: 144-155

Ricker, W. E. (1975). Computation and interpretation of biological statistics of fish populations. Bull. Fish. Res. Bd Can. 191: 1-382

Russell, B. C., Anderson, G. R. V., Talbot, F. H. (1977). Seasonality and recruitment of coral reef fishes. Aust. J. mar. Freshwat. Res. 28: 521-528

Russell, B. C., Talbot, F. H., Domm, S. B. (1974). Patterns of colonization of artificial reefs by coral reef fishes. Proc. 2nd Int. Coral Reefs Symposium 1: 207-215

Sale, P. F. (1977). Maintenance of high diversity on coral reef fish communities. Am. Nat. 111: 337-359

Sale, P. F. (1980). The ecology of fishes of coral reefs. Oceanogr. mar. Biol. A. Rev. 18: 367-421
Sale, P. F., Dybdahl, R. (1975). Determinants of community structure for coral reef fishes in an experimental habitat. Ecology 56: 1343-1355

Sale, P. F., Dybdahl, R. (1978). Determinants of community structure for coral reef fishes in isolated coral heads at lagoonal and reef slope sites. Oecologia 34:57-74

Sutcliffe, W. H. Jr., Drinkwater, K., Muir, B. S. (1977). Correlations of fish catch and environmental factors in the Gulf of Maine. J. Fish. Res. Bd Can. 34: 19-30

Sutcliffe, W. H. Jr., Loucks, R. H., Drinkwater, K. F. (1976). Coastal circulation and physical oceanography of the Scotian Shelf and the Gulf of Maine. J. Fish. Res. Bd Can. 33: 98-115

Talbot, F. H., Russell, B. C., Anderson, G. R. V. (1978). Coral reef fish communities: unstable, high diversity systems? Ecol. Monogr. 48: 425-440

Watson, W., Leis, J. M. (1974). Ichthyoplankton of Kaneohe Bay, Hawaii; a one year study of fish eggs and larvae. Univ. of Hawaii Sea Grant Program, Honolulu, Technical Rep. 75-1

Williams, D. McB. (1979). Factors influencing the distribution and abundance of pomacentrids (Pisces: Pomacentridae) on small patch reefs in the One Tree Lagoon (Great Barrier Reef). Ph. D. thesis, University of Sydney, Australia

Williams, D. McB. (1980). Dynamics of the pomacentrid community on small patch reefs in One Tree Lagoon (Great Barrier Reef). Bull. mar. Sci. 30: 159-170

Williams, D. McB., Sale, P. F. (1981). Spatial and temporal patterns of recruitment of juvenile coral reef fishes to coral habitats within One Tree Lagoon, Great Barrier Reef. Mar. Biol. 65: 245-253

Yamamoto, T. (1976). Seasonal variations in abundance, size compositions and distributional patterns of residing damselfishes in Sesoko Island, Okinawa. Sesoko Mar. Sc. Lab. Tech. Rep. 4: 19-41 